\title{
Recurrent candidiasis and early-onset gastric cancer in a patient with a genetically defined partial MYD88 defect
}

\author{
Ingrid P. Vogelaar ${ }^{1} \cdot$ Marjolijn J. L. Ligtenberg ${ }^{1,2} \cdot$ Rachel S. van der Post $^{2}$ • \\ Richarda M. de Voer ${ }^{1}$ - C. Marleen Kets ${ }^{1}$. Trees J. G. Jansen ${ }^{3}$ Liesbeth Jacobs ${ }^{3}$. \\ Gerty Schreibelt ${ }^{4} \cdot$ International Gastric Cancer Genetics Group • \\ I. Jolanda M. de Vries ${ }^{4,5} \cdot$ Mihai G. Netea ${ }^{3}$ Nicoline Hoogerbrugge $^{1}$
}

Published online: 23 December 2015

(c) The Author(s) 2015. This article is published with open access at Springerlink.com

\begin{abstract}
Gastric cancer is caused by both genetic and environmental factors. A woman who suffered from recurrent candidiasis throughout her life developed diffusetype gastric cancer at the age of 23 years. Using wholeexome sequencing we identified a germline homozygous missense variant in MYD88. Immunological assays on peripheral blood mononuclear cells revealed an impaired immune response upon stimulation with Candida albicans, characterized by a defective production of the cytokine interleukin-17. Our data suggest that a genetic defect in MYD88 results in an impaired immune response and may increase gastric cancer risk.
\end{abstract}

Keywords MYD88 - Gastric cancer - Candida albicans . Interleukin-17 - Th17 response

Ingrid P. Vogelaar and Marjolijn J. L. Ligtenberg have contributed equally to this work.

International Gastric Cancer Genetics Group. See study members referred in "Appendix" section.

Nicoline Hoogerbrugge

nicoline.hoogerbrugge@ radboudumc.nl

1 Department of Human Genetics, Radboud university medical center, P.O. Box 9101, 6500 HB Nijmegen, The Netherlands

2 Department of Pathology, Radboud university medical center, Nijmegen, The Netherlands

3 Department of Internal Medicine, Radboud university medical center, Nijmegen, The Netherlands

4 Department of Tumor Immunology, Radboud university medical center, Nijmegen, The Netherlands

5 Department of Medical Oncology, Radboud university medical center, Nijmegen, The Netherlands

\section{Introduction}

GC is a multifactorial disease with a low survival rate in which both genetic and environmental factors are involved. Infection with Helicobacter pylori is an important risk factor for GC [1].

Approximately 1-3\% of GC cases fulfill the criteria for Hereditary Diffuse Gastric Cancer (HDGC; MIM 137215), a cancer predisposition syndrome characterized by earlyonset diffuse GC. In approximately $20 \%$ of the families fulfilling the HDGC criteria a germline mutation can be found in the $C D H 1$ gene encoding the E-cadherin protein [2-4]. Recently also CTNNA1 and MAP3K6 are described as putative gastric cancer predisposition genes $[5,6]$, but in the majority of cases the underlying genetic cause remains unknown. In this study we report the case of a 23-year-old woman with diffuse-type GC and recurrent candidiasis, in whom we identified a novel germline homozygous MYD 88 variant.

\section{Materials and methods}

\section{Genetic analysis of the 23-year-old gastric cancer patient}

Genomic DNA was extracted from peripheral blood cells and hybridized to Affymetrix SNP6.0 arrays (Affymetrix, Santa Clara, CA, USA) according to the manufacturer's protocol. The genotype was generated using the Birdseed analysis software incorporated in the Affymetrix Genotyping Console v2.1 (Affymetrix). Detected copy number variants (CNVs) were compared to a set of healthy controls, as described previously [7], to exclude regions of normal variation. 
Massive parallel whole-exome sequencing was performed after DNA enrichment using the human SureSelect $50 \mathrm{Mb}$ kit (version 2, Agilent Technologies, Santa Clara, CA, United States) on a 5500XL SOLiD platform (Life Technologies, Bleiswijk, The Netherlands). Reads were mapped to the hg19 reference genome using SOLiD BioScope software (Life Technologies) [8]. Variants were annotated using an in-house annotation pipeline, as described previously [8]. Briefly, from our total set of variants we selected high-confidence ( $\geq 5$ variant reads and/or $\geq 20 \%$ variant reads) non-synonymous variants with a SNP frequency in dbSNP (v132) below $1 \%$ that were present at most once in our in-house variant database containing 2096 exomes (the majority of European ancestry) [8].

Missense variants were considered putatively pathogenic when the affected nucleotide was highly conserved (PhyloP $\geq 3.0$ ) and if two of the following three in silico prediction programs considered this variant deleterious/damaging: SIFT [9], PolyPhen-2 [10], and Align GVGD [11] [all incorporated in the Alamut 2.0 software package (Interactive Biosoftware, Rouen, France)].

\section{Cohort screening for MYD88 variants}

Our cohort of gastric cancer patients consisted of 126 additional $\mathrm{CDHI}$ mutation-negative index patients that meet one of the 2010 HDGC criteria, with the exception that all types of GC histology were included [12]. Germline DNA of these patients was analyzed for mutations in MYD88 (NM_001172567.1) using either Sanger sequencing $(\mathrm{n}=41)$, ion semiconductor sequencing $(\mathrm{n}=63)$ (PGM, Life Technologies) or whole-exome sequencing $(\mathrm{n}=22$, see above). A cohort of 183 healthy individuals from Turkish or Pakistani descent were analyzed for the MYD88 variant using Sanger sequencing.

For Sanger sequencing the full coding sequence of MYD88, including splice junctions, was amplified using polymerase chain reaction (primer sequences and PCR conditions are available on request) and screened for mutations using Big-Dye terminator sequencing (BigDye Terminators (v 1.1) Applied Biosystems, USA). Analysis was performed on an ABI 3730 DNA Analyzer (Applied Biosystems). Subsequently, data was analyzed for variants using Chromas Lite (Technelysium, South Brisbane, Australia).

Ion semiconductor sequencing was performed using a custom designed multiplex Ion AmpliSeq ${ }^{\mathrm{TM}}$ PCR primer panel (Life Technologies) according to the manufacturer's protocol. Briefly, for the library preparation, four DNA samples from our gastric cancer patient cohort were pooled equimolarly and $10 \mathrm{ng}$ of DNA was used for AmpliSeq amplification. Each pool was barcoded with Ion Xpress
Barcode adapters (Life Technologies). The barcoded libraries were purified using Agencourt AMPure XP beads (Beckman Coulter Genomics, High Wycombe, UK), pooled and diluted for use in a 200-bp amplification run on an OneTouch emulsion PCR system (Life Technologies). Before loading onto the 316 chip, sequencing primer and polymerase were added to the final enriched spheres. SeqNext software (JSI Medical Systems) was used for mapping and analysis of the data. All amplicons were analyzed at a coverage of at least $150 \times$. The identified variant was validated in the individual DNA samples of the pool using Sanger sequencing as described above.

\section{Immunological assays}

The cytokine production capacity was assessed as previously described [13]. Briefly, venous blood was collected into EDTA tubes and primary blood mononuclear cells (PBMCs) were isolated by density centrifugation of blood diluted 1:1 in PBS over Ficoll-Paque (Pharmacia Biotech AB, Uppsala, Sweden). Cells were washed three times with PBS and resuspended in RPMI 1640 (Dutch modified) supplemented with $50 \mathrm{mg} / \mathrm{L}$ gentamicin, $2 \mathrm{mM} \mathrm{L-glu-}$ tamine, and $1 \mathrm{mM}$ pyruvate. Cells were counted on a Coulter Counter Z (Beckman Coulter, Mijdrecht, the Netherlands) and adjusted to $5 \times 10^{6}$ cells $/ \mathrm{mL}$. PBMCs $\left(5 \times 10^{5}\right)$ in a $100 \mu \mathrm{L}$ volume were added to round-bottom 96-well plates (Greiner, Alphen a/d Rijn, the Netherlands) and incubated with either $100 \mu \mathrm{L}$ of culture medium (negative control) or one of the stimuli described for $24 \mathrm{~h}$ (TNF $\alpha$, IL-6), $48 \mathrm{~h}$ (IFN- $\gamma$ ) and/or 7 days (IL-17 and IL22). Cytokine production was tested after stimulation of PBMCs with: lipopolysaccharide (LPS) derived from E. coli $(10 \mathrm{ng} / \mathrm{mL})$, heat-killed C. albicans $\left(10^{5}\right.$ microorganisms $/ \mathrm{mL})$, heat-killed H. pylori $\left(10^{7}\right.$ microorganisms/ $\mathrm{mL})$, heat-killed $S$. aureus $\left(10^{7}\right.$ microorganisms $\left./ \mathrm{mL}\right)$, recombinant IL-1 $\beta$ or IL-23 $(100 \mathrm{ng} / \mathrm{mL})$, and recombinant IL-12 or IL-18 $(10 \mathrm{ng} / \mathrm{mL})$ after $24 \mathrm{~h}$ and 7 days. $10 \%$ human pooled serum was added when PBMCs were incubated during 7 days. After incubation the supernatants were stored at $-20{ }^{\circ} \mathrm{C}$ until assay. Experiments were performed in duplicate.

\section{Results}

\section{Early-onset gastric cancer patient with extensive infectious phenotype}

The patient first presented with pain in the left upper abdomen at the age of 23 years. She was diagnosed with an $H$. pylori infection, for which eradication treatment was given. As the abdominal pain continued, a gastroduodenoscopy was 
performed, which revealed a gastric ulcer. Histopathological analyses of biopsies showed a signet ring cell carcinoma and moderate chronic active, non-specific gastritis (Fig. 1a-c). The patient was treated with neoadjuvant chemotherapy resulting in almost complete regression of the gastric tumor at the time of surgery (Fig. 1d).

Because of the early-onset diffuse GC the patient was referred for genetic counseling. Family history revealed distantly related parents of Kurdish descent, six unaffected siblings and no other relatives with GC. Her medical history revealed that she lost her fingernails (onycholysis) at the age of two years. Throughout her life, she suffered from recurrent vaginal Candida albicans infections and recurrent fungal infections, in particular dermatophytic onychomycosis, of which at clinical examination pigmented rash could be observed in her neck, between her breasts and at the rim of her fingernails. Her medical history was negative for allergies and pyogenic infections.

\section{Identification of a novel homozygous missense variant in MYD88}

The patient developed diffuse-type GC at a very young age and therefore meets the $\mathrm{CDH} 1$ testing criteria [12]. $\mathrm{CDH}$ germline mutation analysis was performed, but no germline
$\mathrm{CDHl}$ alterations were found by sequencing analysis of the entire open reading frame, including intron-exon boundaries, or Multiplex Ligation-dependent Probe Amplification (MLPA) of all exons. Therefore, further research on possible underlying genetic aberrations was performed. Copy number profiling using SNP6.0 arrays showed no significant copy number variations, but revealed large areas with loss of heterozygous calls, in agreement with parental consanguinity (data not shown).

Subsequently, whole-exome sequencing on germline DNA from the patient was performed. No putative pathogenic mutations in other cancer predisposition genes among which CTNNAl and MAP3K6 were detected. The heterozygous missense variant in PMS1 that was validated using Sanger sequencing (Table 1) probably does not contribute to the phenotype of the patient. Because the parents were distantly related, we focused our data-analysis on homozygous variants with a variant percentage $\geq 80 \%$ $(\mathrm{n}=17)$. Five variants that were putatively pathogenic (one protein-truncating variant and four missense variants) were validated using Sanger sequencing, of which the missense variant (c.712C $>$ T, p.(Arg238Cys)) in the myeloid differentiation primary response 88 (MYD88) gene was considered most relevant. This variant affects a moderately conserved nucleotide (phyloP 3.76) of a highly conserved amino acid in

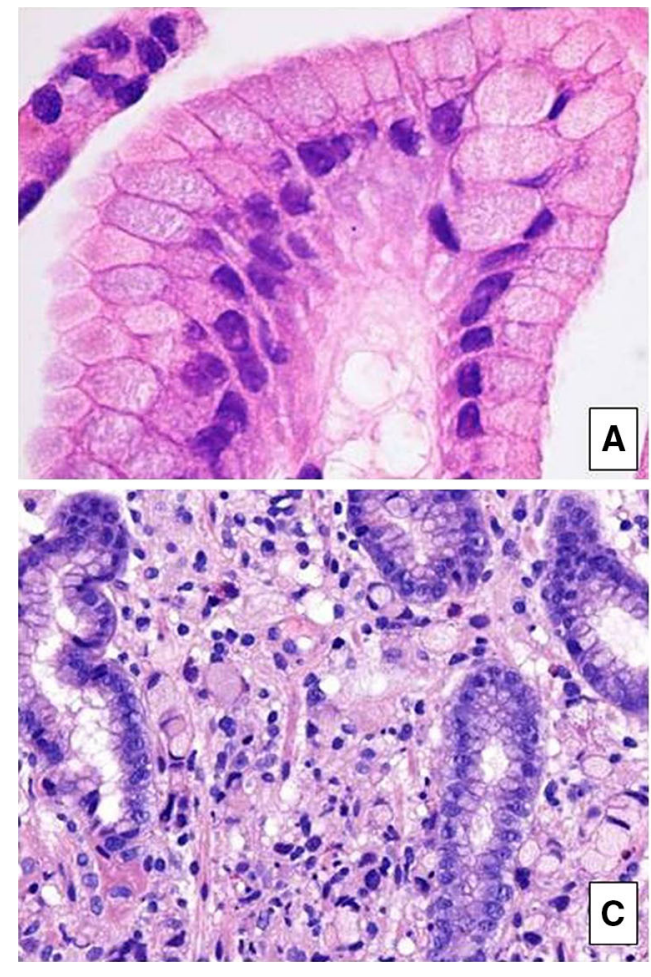

Fig. 1 Signet ring cell carcinoma of the patient. Note the typical spreading of single cells in the gastric glands $(\mathbf{a}, \mathbf{b})$ and invasive signet ring cells between glands in the lamina propria (c).

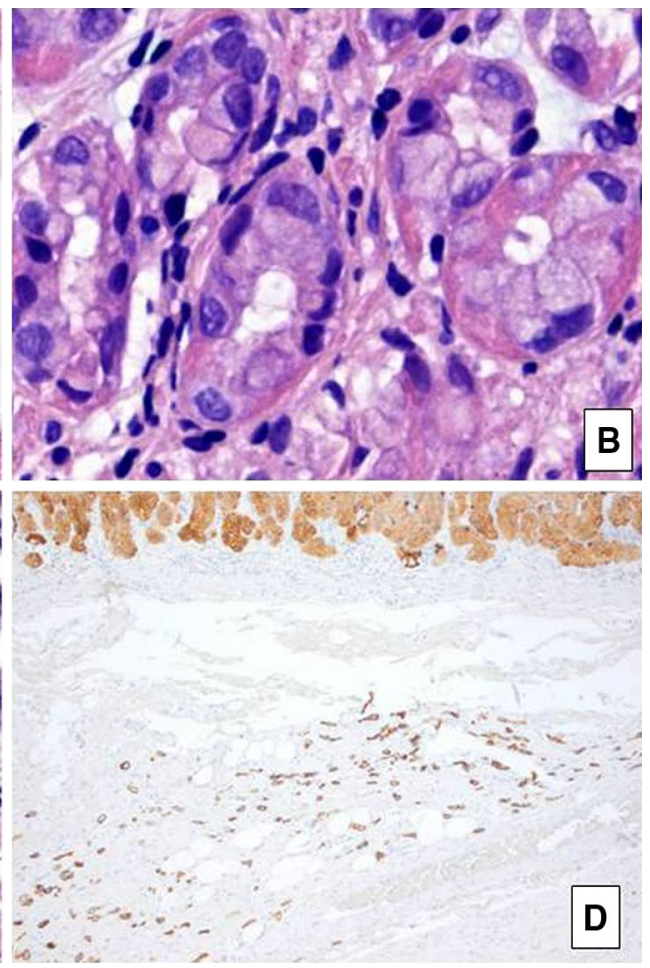

Gastrectomy shows patchy remnants of cancer cells in the submucosa (d cytokeratin 8.18 stain) [original magnifications $400 \times(\mathbf{a}-\mathbf{c}) ; 50 \times$ (d)] 


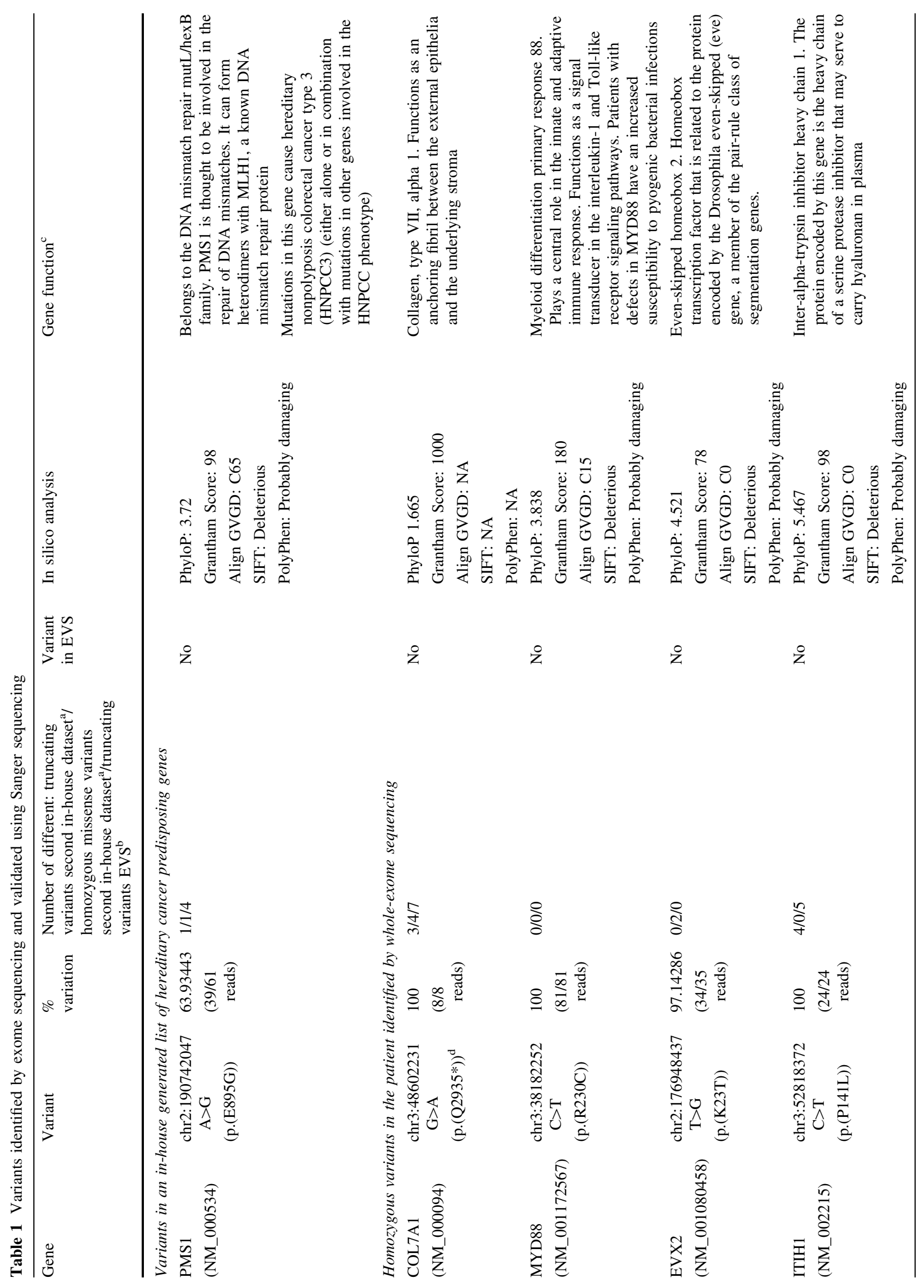




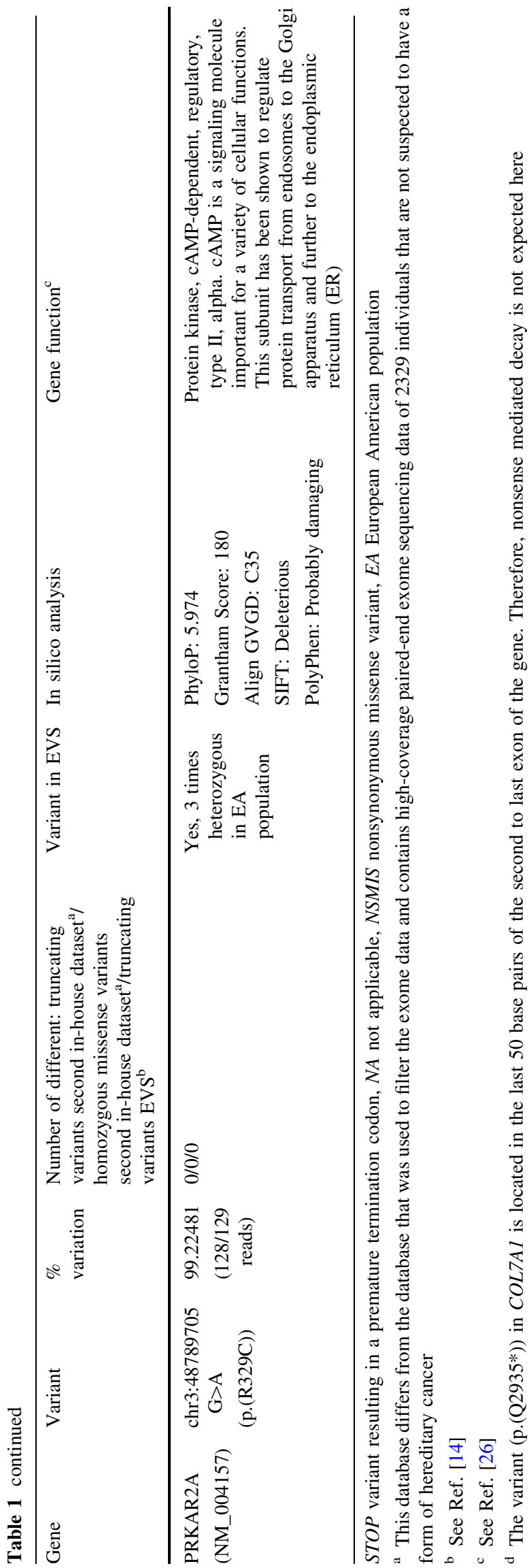

the Toll/interleukin-1 receptor (TIR) homology domain of the gene and is predicted to be damaging to protein function using in silico prediction programs. For the list of all validated variants and occurrence of variation in the corresponding genes in control databases, see Table 1.

\section{Variation in the MYD88 gene in healthy controls and an additional cohort of gastric cancer patients is rare}

To assess the variation in MYD88 in control databases, we extracted all the germline variation in the coding region from MYD 88 from a second in-house dataset and the Exome Variant Server (EVS) [14]. Furthermore, we used The Cancer Genome Atlas (containing 220 gastric adenocarcinomas) to determine the amount of somatic variation in the MYD88 gene [15]. Germline and somatic variation in the coding region of MYD88 is rare with less than $0.5 \%$ heterozygous missense mutations in about 8832 individuals. The variant detected in our patient is not present in any of the commonly used control databases nor in 183 healthy controls from Turkish or Pakistani descent. Moreover, only one other heterozygous MYD88 variant (c.704G $>$ A, p.(G235D)) was identified by targeted resequencing of the coding regions of the gene in 126 additional patients with early-onset and/or familial GC. In silico analyses predicted this variant to be benign. These results indicate that variants in MYD88 are infrequent in both controls and GC patients.

\section{Immunological assays reveal functional relevance of the MYD88 variant}

Since MYD88 plays a central role in the immune response, we analyzed the cytokine production of peripheral blood mononuclear cells (PBMCs) of the patient, stimulated with heat-killed C. albicans and H. pylori. As expected based on the infections seen in patients with MYD88 deficiency [16], a specific defect in the production of Th17 cytokine IL-17 (Fig. 2, left panel) was observed upon re-stimulation of the patients' PBMCs with $C$. albicans. In healthy individuals that have been exposed to H.pylori, an enhanced IL-17 production is observed after re-stimulation of the PBMCs with this pathogen [17]. When we performed this assay for the patient, no difference was observed compared to controls (Fig. 2, right panel). The immune response to Toll-like receptor stimuli and S. aureus was normal (data not shown).

\section{Discussion}

In this study we report the case of a young woman with diffuse-type GC in which we did not find a germline mutation in the known cancer predisposition genes like 


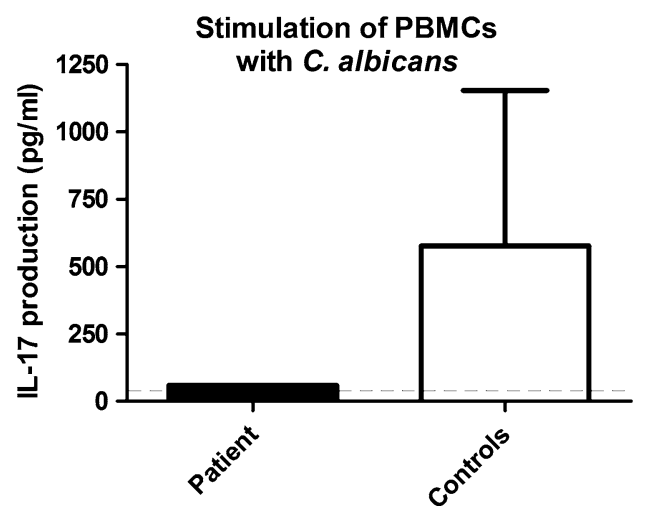

Fig. 2 Immunological assays on peripheral blood mononuclear cells (PBMCs) from the patient with the MYD88 variant. Assays revealed an impaired immune response upon stimulation with C. albicans (left panel), characterized by a specific defect in production of the Th17

CDH1, CTTNA1 and MAP3K6 that are associated with diffuse gastric cancer susceptibility. Using whole-exome sequencing, we identified a novel germline homozygous MYD88 variant, which probably explains the patient's vulnerability to $C$. albicans and other infections that might have contributed to the development of her gastric cancer.

MYD88 plays a central role as a mediator of the innate immune response to infections. The infectious phenotype of autosomal recessive MYD88 deficiency (OMIM 612260 ) is dominated by invasive pyogenic infections and the main bacteria isolated in cases of invasive infection are Staphylococcus pneumoniae, S. aureus, and Pseudomonas aeruginosa. Also fungal infections, for example caused by the yeast $C$. albicans, are described in patients with MYD88 deficiency [18]. In mice it was shown that MYD88 deficiency leads to an early and rapid development of $H$. pylori-induced gastric dysplasia [19].

GC was not reported in the twenty-four patients described with MYD88 deficiency, of which the oldest patient was aged 20 at time of publication [16]. However, 'classic' MYD88 deficiency has a high mortality at an early age, and therefore patients likely die too young to develop GC [20]. In contrast to the functional analyses described for these MYD88 deficiency patients, our assays indicate that our patient suffers from a milder form of MYD88 deficiency, which matches her clinical phenotype and is probably explained by the type of MYD 88 mutation, which to the best of our knowledge was not described before.

Therefore, we hypothesize that, in our patient, the partial MYD88 defect causes an impaired immune response, resulting in recurrent $C$. albicans infections and nonspecific gastritis increasing the risk of signet ring cell carcinoma of the stomach wall. Whether GC is more frequently diagnosed in patients with recurrent fungal infections is unknown, but it is known that patients with simultaneous $C$. albicans and $H$. pylori infection have an

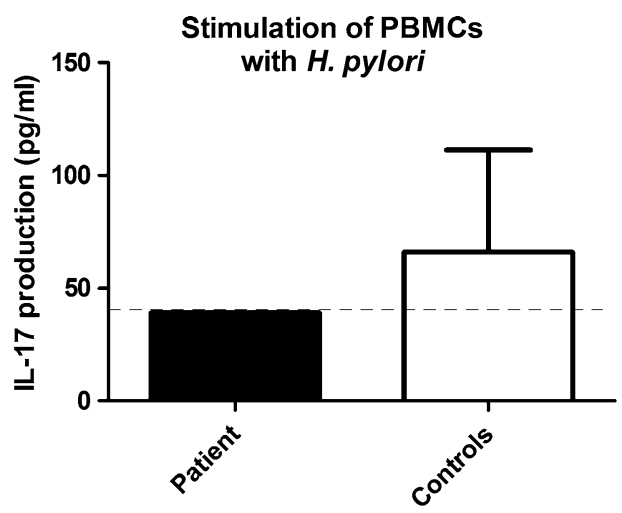

cytokine IL-17. Immune response to Helicobacter pylori was normal (right panel). The detection limit for the assay is indicated with the dotted line. Values depicted are the means with standard deviation (SD)

increased risk of developing gastric ulcers [21]. C. albicans is able to degrade E-cadherin in vitro [22], which may be a tumor initiating event in the development of gastric signet ring cell carcinoma similar to E-cadherin inactivation by mutations in its gene $\mathrm{CDH} 1$. In line with our hypothesis that impaired immune response might lead to an increased risk of gastric cancer, the co-occurrence of $C$. albicans and signet ring cell carcinoma of the stomach was previously described in a patient with acquired immune deficiency syndrome [23], who as a group have a 1.5-fold increased risk to develop GC [24]. Moreover, a tenfold increased GC risk is seen in patients with common variable immunodeficiency disorders (CVIDs) [25].

Due to neoadjuvant chemotherapy the patient received prior to surgery, no molecular analyses were possible on resection material. Therefore, we cannot exclude that, although this has not been described for other DGC patients thus far, two somatic mutations in either $\mathrm{CDH} 1$ or one of the recently described candidate genes CTNNA1 or MAP3K6 [5, 6] are causal for the DGC development. The fact that the cancer has arisen by chance can also not be excluded, but based on the extremely young age of the patient we consider this very unlikely.

No additional germline mutations in MYD88 were found in our cohort of 126 patients suspected of hereditary gastric cancer. This implies that germline mutations in MYD88 in GC patients are rare. Rather than screening complete cohorts of patients for this type of mutations, we suggest more thorough anamnestic analysis of GC patients to unravel whether a (partial) immunodeficiency could be causal for GC development.

In conclusion, we identified a functionally relevant homozygous missense variant in MYD88 and a defective Th17 response in a patient with recurrent infections and early-onset gastric cancer. The missense variant in MYD88 is the likely cause of persistent fungal infections that 
ultimately may have led to the development of early-onset gastric cancer in this patient. Future research is needed to unravel whether such immune deficiencies are a more common genetic risk factor for gastric cancer development.

Acknowledgments This work was supported by the Radboudumc Center for Oncology, granted in 2010, the Deutsche Krebshilfe Grant 70-2371, the Portuguese Foundation for Science and Technology (FCT) (Projects Ref. FCT PTDC/SAU-GMG/110785/2009 and Postdoc grant SFRH/BPD/79499/2011 to HP "financiados no âmbito do Programa Operacional Temático Factores de Competitividade (COMPETE) e comparticipado pelo fundo Comunitário Europeu FEDER”). M.G.N. was supported by an ERC-Consolidator Grant (310372). The authors would like to thank prof. dr. Carl Figdor for fruitful scientific discussions and Hanna Feunekes for help with the validation work. The $H$. pylori strains were kindly provided by prof. dr. Christina Vandenbroucke-Grauls and the DNA samples of healthy controls were provided by Margit Schraders, Jaap Oostrik and Muhammad Imran Khan.

\section{Compliance with ethical standards}

Conflict of interest The authors declare that they have no conflict of interest.

Ethical approval All procedures performed in studies involving human participants were in accordance with the ethical standards of the institutional and/or national research committee and with the 1964 Helsinki declaration and its later amendments or comparable ethical standards. The study was approved by the medical ethics committee of the Radboud university medical center, reference number 2013/201. Informed consent was obtained from all individual participants included in the study.

Open Access This article is distributed under the terms of the Creative Commons Attribution 4.0 International License (http://crea tivecommons.org/licenses/by/4.0/), which permits unrestricted use, distribution, and reproduction in any medium, provided you give appropriate credit to the original author(s) and the source, provide a link to the Creative Commons license, and indicate if changes were made.

\section{Appendix}

International Gastric Cancer Genetics Group: Jan Lubinski, Department of Genetics and Pathology, Pomeranian Medical University, Szczecin, Poland; Anna Jakubowska, Department of Genetics and Pathology, Pomeranian Medical University, Szczecin, Poland; Urszula Teodorczyk, Department of Genetics and Pathology, Pomeranian Medical University, Szczecin, Poland; Hans K. Schackert, Department of Surgical Research, Universitätsklinikum Carl Gustav Carus, Technische Universität Dresden, Dresden, Germany; Cora M. Aalfs, Department of Clinical Genetics, Academic Medical Centre, Amsterdam, The Netherlands; Encarna B. Gómez García, Department of Clinical Genetics, Maastricht University Medical Center, Maastricht, The Netherlands; Guglielmina N. Ranzani, Department of Biology and Biotechnology, University of Pavia, Pavia, Italy;
Valeria Molinaro, Department of Biology and Biotechnology, University of Pavia, Pavia, Italy; Liselotte P. van Hest, Department of Clinical Genetics, VU University Medical Center, Amsterdam, The Netherlands; Frederik J. Hes, Department of Clinical Genetics, Leiden University Medical Center, Leiden, The Netherlands; Elke Holinski-Feder, Medical Genetics Center, München, Germany; Maurizio Genuardi, Institute of Medical Genetics, Catholic University, Rome, Italy; Margreet G.E.M. Ausems, Department of Medical Genetics, University Medical Center Utrecht, The Netherlands; Rolf H. Sijmons, Department of Genetics, University Medical Center Groningen, University of Groningen, The Netherlands; Anja Wagner, Department of Clinical Genetics, Erasmus University Medical Center, Rotterdam, The Netherlands; Lizet E. van der Kolk, Family Cancer Clinic, The Netherlands Cancer Institute, Amsterdam, The Netherlands; Hugo Pinheiro, Expression Regulation in Cancer Group, IPATIMUP, Institute of Molecular Pathology and Immunology of the University of Porto, Porto, Portugal; Carla Oliveira, Expression Regulation in Cancer Group, IPATIMUP, Institute of Molecular Pathology and Immunology of the University of Porto/Department of Pathology and Oncology, Medical Faculty of the University of Porto, Porto, Portugal; Inga Bjørnevoll, Department of Medical Genetics and Pathology, St. Olavs University Hospital, Trondheim, Norway; Hildegunn Høberg Vetti, Western Norway Familial Cancer Center, Center for Medical Genetics and Molecular Medicine, Haukeland University Hospital, Bergen, Norway; J. Han J.M. van Krieken, Department of Pathology, Radboud university medical center, Nijmegen, The Netherlands.

\section{References}

1. Suerbaum S, Michetti P (2002) Helicobacter pylori infection. N Engl J Med 347(15):1175-1186. doi:10.1056/NEJMra020542

2. Benusiglio PR, Malka D, Rouleau E, De Pauw A, Buecher B, Nogues C, Fourme E, Colas C, Coulet F, Warcoin M, Grandjouan S, Sezeur A, Laurent-Puig P, Moliere D, Tlemsani C, Di Maria M, Byrde V, Delaloge S, Blayau M, Caron O (2013) CDH1 germline mutations and the hereditary diffuse gastric and lobular breast cancer syndrome: a multicentre study. J Med Genet 50(7):486-489. doi:10.1136/jmedgenet-2012-101472

3. Hansford S, Kaurah P, Li-Chang H, Woo M, Senz J, Pinheiro H, Schrader KA, Schaeffer DF, Shumansky K, Zogopoulos G, Santos TA, Claro I, Carvalho J, Nielsen C, Padilla S, Lum A, Talhouk A, Baker-Lange K, Richardson S, Lewis I, Lindor NM, Pennell E, MacMillan A, Fernandez B, Keller G, Lynch H, Shah SP, Guilford P, Gallinger S, Corso G, Roviello F, Caldas C, Oliveira C, Pharoah PD, Huntsman DG (2015) Hereditary diffuse gastric cancer syndrome: CDH1 mutations and beyond. JAMA Oncol 1(1):23-32. doi:10.1001/jamaoncol.2014.168

4. van der Post RS, Vogelaar IP, Manders P, van der Kolk LE, Cats A, van Hest LP, Sijmons R, Aalfs CM, Ausems MG, Gomez Garcia EB, Wagner A, Hes FJ, Arts N, Mensenkamp AR, van Krieken JH, Hoogerbrugge N, Ligtenberg MJ (2015) Accuracy of 
hereditary diffuse gastric cancer testing criteria and outcomes in patients with a germline mutation in CDH1. Gastroenterology 149(4):897-906 e819. doi:10.1053/j.gastro.2015.06.003

5. Majewski IJ, Kluijt I, Cats A, Scerri TS, de Jong D, Kluin RJ, Hansford S, Hogervorst FB, Bosma AJ, Hofland I, Winter M, Huntsman D, Jonkers J, Bahlo M, Bernards R (2013) An alpha-Ecatenin (CTNNA1) mutation in hereditary diffuse gastric cancer. J Pathol 229(4):621-629. doi:10.1002/path.4152

6. Gaston D, Hansford S, Oliveira C, Nightingale M, Pinheiro H, Macgillivray C, Kaurah P, Rideout AL, Steele P, Soares G, Huang WY, Whitehouse S, Blowers S, LeBlanc MA, Jiang H, Greer W, Samuels ME, Orr A, Fernandez CV, Majewski J, Ludman M, Dyack S, Penney LS, McMaster CR, Huntsman D, Bedard K (2014) Germline mutations in MAP3K6 are associated with familial gastric cancer. PLoS Genet 10(10):e1004669. doi:10.1371/journal.pgen.1004669

7. Venkatachalam R, Verwiel ET, Kamping EJ, Hoenselaar E, Gorgens H, Schackert HK, van Krieken JH, Ligtenberg MJ, Hoogerbrugge N, van Kessel AG, Kuiper RP (2011) Identification of candidate predisposing copy number variants in familial and early-onset colorectal cancer patients. Int $\mathrm{J}$ Cancer 129(7):1635-1642. doi:10.1002/ijc.25821

8. Vissers LE, de Ligt J, Gilissen C, Janssen I, Steehouwer M, de Vries P, van Lier B, Arts P, Wieskamp N, del Rosario M, van Bon BW, Hoischen A, de Vries BB, Brunner HG, Veltman JA (2010) A de novo paradigm for mental retardation. Nat Genet 42(12):1109-1112. doi:10.1038/ng.712

9. Kumar P, Henikoff S, Ng PC (2009) Predicting the effects of coding non-synonymous variants on protein function using the SIFT algorithm. Nat Protoc 4(7):1073-1081. doi:10.1038/nprot. 2009.86

10. Adzhubei IA, Schmidt S, Peshkin L, Ramensky VE, Gerasimova A, Bork P, Kondrashov AS, Sunyaev SR (2010) A method and server for predicting damaging missense mutations. Nat Methods 7(4):248-249. doi:10.1038/nmeth0410-248

11. Tavtigian SV, Deffenbaugh AM, Yin L, Judkins T, Scholl T, Samollow PB, de Silva D, Zharkikh A, Thomas A (2006) Comprehensive statistical study of 452 BRCA1 missense substitutions with classification of eight recurrent substitutions as neutral. J Med Genet 43(4):295-305. doi:10.1136/jmg.2005.033878

12. Fitzgerald RC, Hardwick R, Huntsman D, Carneiro F, Guilford P, Blair V, Chung DC, Norton J, Ragunath K, Van Krieken JH, Dwerryhouse S, Caldas C, International Gastric Cancer Linkage C (2010) Hereditary diffuse gastric cancer: updated consensus guidelines for clinical management and directions for future research. J Med Genet 47(7):436-444. doi:10.1136/jmg.2009.074237

13. van de Veerdonk FL, Plantinga TS, Hoischen A, Smeekens SP, Joosten LA, Gilissen C, Arts P, Rosentul DC, Carmichael AJ, Smits-van der Graaf CA, Kullberg BJ, van der Meer JW, Lilic D, Veltman JA, Netea MG (2011) STAT1 mutations in autosomal dominant chronic mucocutaneous candidiasis. N Engl J Med 365(1):54-61. doi:10.1056/NEJMoa1 100102

14. Exome Variant Server NESPE, Seattle, WA Exome Variant Server, NHLBI Exome Sequencing Project (ESP), Seattle, WA. http://evs.gs. washington.edu/EVS/

15. Cancer Genome Atlas Research Network (2014) Comprehensive molecular characterization of gastric adenocarcinoma. Nature 513(7517):202-209. doi:10.1038/nature13480

16. von Bernuth $\mathrm{H}$, Picard C, Jin Z, Pankla R, Xiao H, Ku CL, Chrabieh M, Mustapha IB, Ghandil P, Camcioglu Y, Vasconcelos J, Sirvent N, Guedes M, Vitor AB, Herrero-Mata MJ, Arostegui JI, Rodrigo C, Alsina L, Ruiz-Ortiz E, Juan M, Fortuny C, Yague J, Anton J, Pascal M, Chang HH, Janniere L, Rose Y, Garty BZ,
Chapel H, Issekutz A, Marodi L, Rodriguez-Gallego C, Banchereau J, Abel L, Li X, Chaussabel D, Puel A, Casanova JL (2008) Pyogenic bacterial infections in humans with MyD88 deficiency. Science 321(5889):691-696. doi:10.1126/science. 1158298

17. Serelli-Lee V, Ling KL, Ho C, Yeong LH, Lim GK, Ho B, Wong SB (2012) Persistent Helicobacter pylori specific Th17 responses in patients with past $H$. pylori infection are associated with elevated gastric mucosal IL-1beta. PLoS ONE 7(6):e39199. doi:10. 1371/journal.pone.0039199

18. von Bernuth H, Picard C, Puel A, Casanova JL (2012) Experimental and natural infections in MyD88- and IRAK-4-deficient mice and humans. Eur J Immunol 42(12):3126-3135. doi:10. 1002/eji.201242683

19. Banerjee A, Thamphiwatana S, Carmona EM, Rickman B, Doran KS, Obonyo M (2014) Deficiency of the myeloid differentiation primary response molecule MyD88 leads to an early and rapid development of Helicobacter-induced gastric malignancy. Infect Immun 82(1):356-363. doi:10.1128/IAI.01344-13

20. Picard C, von Bernuth H, Ghandil P, Chrabieh M, Levy O, Arkwright PD, McDonald D, Geha RS, Takada H, Krause JC, Creech CB, Ku CL, Ehl S, Marodi L, Al-Muhsen S, Al-Hajjar S, Al-Ghonaium A, Day-Good NK, Holland SM, Gallin JI, Chapel H, Speert DP, Rodriguez-Gallego C, Colino E, Garty BZ, Roifman C, Hara T, Yoshikawa H, Nonoyama S, Domachowske J, Issekutz AC, Tang M, Smart J, Zitnik SE, Hoarau C, Kumararatne DS, Thrasher AJ, Davies EG, Bethune C, Sirvent N, de Ricaud D, Camcioglu Y, Vasconcelos J, Guedes M, Vitor AB, Rodrigo C, Almazan F, Mendez M, Arostegui JI, Alsina L, Fortuny C, Reichenbach J, Verbsky JW, Bossuyt X, Doffinger R, Abel L, Puel A, Casanova JL (2010) Clinical features and outcome of patients with IRAK-4 and MyD88 deficiency. Medicine 89(6):403-425. doi:10.1097/MD.0b013e3181fd8ec3

21. Karczewska E, Wojtas I, Sito E, Trojanowska D, Budak A, Zwolinska-Wcislo M, Wilk A (2009) Assessment of co-existence of Helicobacter pylori and Candida fungi in diseases of the upper gastrointestinal tract. J Physiol Pharmacol 60(Suppl 6):33-39

22. Frank CF, Hostetter MK (2007) Cleavage of E-cadherin: a mechanism for disruption of the intestinal epithelial barrier by Candida albicans. Transl Res 149(4):211-222. doi:10.1016/j.trs1. 2006.11.006

23. Uchida T, Midorikawa J, Takeda H, Shichishima T, Higuchi T, Yui T, Kimura H, Matsuda S, Kariyone S (1989) Signet cell carcinoma of the stomach in a patient with acquired immunodeficiency syndrome: a case report. Jpn J Clin Oncol 19(1):75-78

24. Persson EC, Shiels MS, Dawsey SM, Bhatia K, Anderson LA, Engels EA (2012) Increased risk of stomach and esophageal malignancies in people with AIDS. Gastroenterology 143(4):943-950 e942. doi:10.1053/j.gastro.2012.07.013

25. Dhalla F, da Silva SP, Lucas M, Travis S, Chapel H (2011) Review of gastric cancer risk factors in patients with common variable immunodeficiency disorders, resulting in a proposal for a surveillance programme. Clin Exp Immunol 165(1):1-7. doi:10. 1111/j.1365-2249.2011.04384.x

26. Pruitt KD, Brown GR, Hiatt SM, Thibaud-Nissen F, Astashyn A, Ermolaeva O, Farrell CM, Hart J, Landrum MJ, McGarvey KM, Murphy MR, O'Leary NA, Pujar S, Rajput B, Rangwala SH, Riddick LD, Shkeda A, Sun H, Tamez P, Tully RE, Wallin C, Webb D, Weber J, Wu W, DiCuccio M, Kitts P, Maglott DR, Murphy TD, Ostell JM (2014) RefSeq: an update on mammalian reference sequences. Nucleic Acids Res 42(Database issue):D756-D763. doi:10.1093/nar/gkt1114 